\title{
TOPOLOGICALLY CLOSE PACKED PHASES IN AN EXPERIMENTAL RHENIUM-CONTAINING SINGLE CRYSTAL SUPERALLOY
}

\author{
C.M.F. Rae, M.S.A. Karunaratne, C.J. Small*, R.W. Broomfield*, C.N. Jones* \\ and R.C. Reed \\ University of Cambridge / Rolls-Royce University Technology Centre \\ Department of Materials Science and Metallurgy \\ Pembroke Street, CAMBRIDGE CB2 3QZ, UK \\ * Rolls Royce plc \\ PO Box 31, Derby, DB24 8BJ
}

\begin{abstract}
$\underline{\text { Abstract }}$
The kinetics, morphology and composition of the formation of TCP phases in an experimental alloy containing no tungsten is studied. At high temperature $\mathrm{P}$ phase forms after $20 \mathrm{~h}$, whereas below $950^{\circ} \mathrm{C}$ the phases $\mu$ and $\mathrm{R}$ occur. At lower temperatures a polycrystalline form of $\sigma$ phase is observed which is meta-stable but acts as a nucleation site for the other phases. The phase occurrence and compositions are compared with a thermodynamic model using a rhenium-containing database, and reasonable agreement is found for the $P, R$ and $\sigma$ phases. However the model underestimates the stability of the $\mu$ phase.
\end{abstract}

\section{$\underline{\text { Introduction }}$}

Over the last 25 years additions of the elements tungsten, molybdenum and rhenium to single crystal superalloys have increased greatly and this situation is largely responsible for the improvements in the high temperalure creep and rupture properties that have been achieved [1,2]. However, the amounts of these elements which can usefully be introduced is limited by the formation of the group of phases known as TCP or Topologically Close-Packed phases [3]. The crystal structures consist of close-packed layers of relatively smaller atoms, such as nickel and chromium, with the larger atoms, such as rhenium, tungsten and tantalum, residing in 14,15 or 16 co-ordinated sites between the layers. The number of these sites, centred on one of the so-called Kasper polyhcdra [4], is characteristic of a given TCP phase, and, as a consequence of this, a wide range of compositions are displayed. In general, the close-packed layers have a high degree of coherency with the $\{111\}$ planes of the $\gamma$ and $\gamma^{\prime}$ phases. Frequently, the TCP phases form in an extensive plate-like morphology parallel to the four $\{111\}$ planes. This results in the characteristic needle-like appearance when sectioned in the $\{100\}$ plane. Table 1 lists the crystallography of the phases observed in this work. TCP phases have been shown to have an adverse effect on the mechanical propcrties of alloys $[5,6]$, but, although they are brittle, there is conflicting evidence that they are directly involved in the failure and fracture of single crystal alloys $[7,8,9]$. A major threat posed to these alloys by the formation of TCP phases comes from the loss of the TCP-forming elements, and their potential strengthening effect, from the gamma phase.

The prediction of alloy stability is an important part of the alloy design process and recently the use of thermodynamic modelling of these multi-component alloys has proved to be a very powerful technique $[10,11,12,13,14]$. However the accuracy of this method in predicting interactions in systems of up to 14 components depends on the availability of accurate experimental data on the equilibrium phases. Although TCP phases have bccn studied for many years, and their presence carefully monitored in a great number of alloys, data on the specific nature of the phases formed and their compositions in Re-containing single crystal superalloys are limited in extent $[7,8,9,15]$. Recently $R e$ has been added to the existing Ni-based superalloy database [16], and the work described here forms part of a larger study performed to validate the predictions of this database with respect to TCP formation and to provide further data for development of the model. The alloy described here, RR2071, is a second-generation single crystal superalloy containing $\sim 3$ wt $\%$ of rhenium comparable with the commercial superalloys such as CMSX-4. It is unusual in that it contains no tungsten and exhibits all four TCP phases typically found in single crystal alloys. This paper describes the TCP phases formed in the alloy, their composition and structure and demonstrates the role of sigma nucleation in the formation of the other TCP phases. Comparison with CMSX-4 and Alloy 800 $[7,15]$ allows the effect of the replacement of tungsten by molybdenum to be explored.

\section{Experimental Details}

The alloy RR2071 used in this study is an experimental rheniumcontaining single crystal alloy. Table 2 gives its composition together with that of CMSX-4 and Alloy 800 [15]. In RR2071 (in comparison with CMSX-4) the tungsten is replaced by a similar atomic percent of the lighter element molybdenum with the aim of reducing the density of the alloy. Other modifications are a slightly increased titanium percentage and the addition of a small amount of niobium.

Single crystal bars RR2071 were supplied by Rolls-Royce plc, (Derby, U.K.) in the fully heat-treated condition which involved: (i) solutioning at $1295^{\circ} \mathrm{C}$ for 6 hours, (ii) a primary age of 4 hours at $1130^{\circ} \mathrm{C}$ and finally (iii) a secondary age of 16 hours at $870^{\circ} \mathrm{C}$. Samples were sealed under vacuum in silica tubes after flushing with argon and annealed for various times and temperatures. Some samples were annealed for shorter times in air and this did not have any effect on the formation of the TCP phases.

Specimens for TEM examination were polished using $20 \%$ perchloric acid in acetic acid at $10^{\circ} \mathrm{C}$ and 50V. A JEOL 2000FX 
electron microscope was used to identify and analyse the phases using selected area diffraction and Energy-Dispersive Spectrometry. For the X-ray analysis the TCP phases were extracted from the $\gamma / \gamma^{\prime}$ matrix using the techniques described in Reed et. al. [17].
Bulk specimens were prepared by mechanical abrasion finishing with a polish using colloidal silica for at least 20 minutes. The samples were examined in the JEOL 6340F, field emission gun scanning electron microscope using back-scattered electron contrast.

\begin{tabular}{|l|l|l|l|l|l|l|}
\hline $\begin{array}{l}\text { TCP } \\
\text { Phase }\end{array}$ & System & $\begin{array}{l}\text { Space } \\
\text { Group }\end{array}$ & $\begin{array}{l}\text { Space } \\
\text { Group No. }\end{array}$ & $\begin{array}{l}\text { Atoms per } \\
\text { Unit Cell }\end{array}$ & $\begin{array}{l}\text { Lattice } \\
\text { Parameter }\end{array}$ & $\alpha$ \\
\hline$\sigma$ & Tetragonal & P4/mnm & 136 & 30 & $\mathrm{a}=\mathrm{b}=0.878 \mathrm{~nm}, \mathrm{c}=0.454 \mathrm{~nm}$ & $90^{\circ}$ \\
\hline $\mathrm{P}$ & Orthorhombic & Pnma & 62 & 56 & $\begin{array}{l}\mathrm{a}=1.698 \mathrm{~nm}, \mathrm{~b}=0.475 \mathrm{~nm} \\
\mathrm{c}=0.907 \mathrm{~nm}\end{array}$ & $90^{\circ}$ \\
\hline$\mu$ & Rhombohedral & R-3m & 166 & $\begin{array}{l}13 \\
\text { (hex. 39) }\end{array}$ & $\begin{array}{l}\mathrm{a}=\mathrm{b}=\mathrm{c}=0.904 \mathrm{~nm} \\
\mathrm{a}=\mathrm{b}=0.4755 \mathrm{~nm}, \mathrm{c}=2.583 \mathrm{~nm}\end{array}$ & $\begin{array}{l}30.5^{\circ} \\
120^{\circ}\end{array}$ \\
\hline $\mathrm{R}$ & Rhombohedral & R-3 & 148 & $\begin{array}{l}53 \\
\text { (hex. 159) }\end{array}$ & $\mathrm{a}=\mathrm{b}=1.093 \mathrm{~nm}, \mathrm{c}=1.934 \mathrm{~nm}$ & $120^{\circ}$ \\
\hline
\end{tabular}

Table 1: Crystallography of the TCP Phases.

\begin{tabular}{|l|l|l|l|l|l|l|l|l|l|l|l|}
\hline Wt \% & $\mathrm{Ni}$ & $\mathrm{Co}$ & $\mathrm{Cr}$ & $\mathrm{Mo}$ & $\mathrm{W}$ & $\mathrm{Re}$ & $\mathrm{Al}$ & $\mathrm{Ti}$ & $\mathrm{Ta}$ & $\mathrm{Nb}$ & $\mathrm{Hf}$ \\
\hline RR2071 & 62.0 & 9.50 & 6.60 & 4.50 & 0.00 & 2.80 & 5.60 & 1.30 & 7.30 & 0.30 & 0.10 \\
\hline CMSX-4 & 61.7 & 9.0 & 6.50 & 0.60 & 6.00 & 3.00 & 5.6 & 1.00 & 6.50 & 0.00 & 0.10 \\
\hline Alloy 800 & 63.6 & 7.5 & 8.0 & 1.5 & 4.0 & 3.0 & 5.8 & 1.5 & 5.0 & 0.0 & 0.0 \\
\hline
\end{tabular}

Table 2: Alloy Compositions in Wt \%.

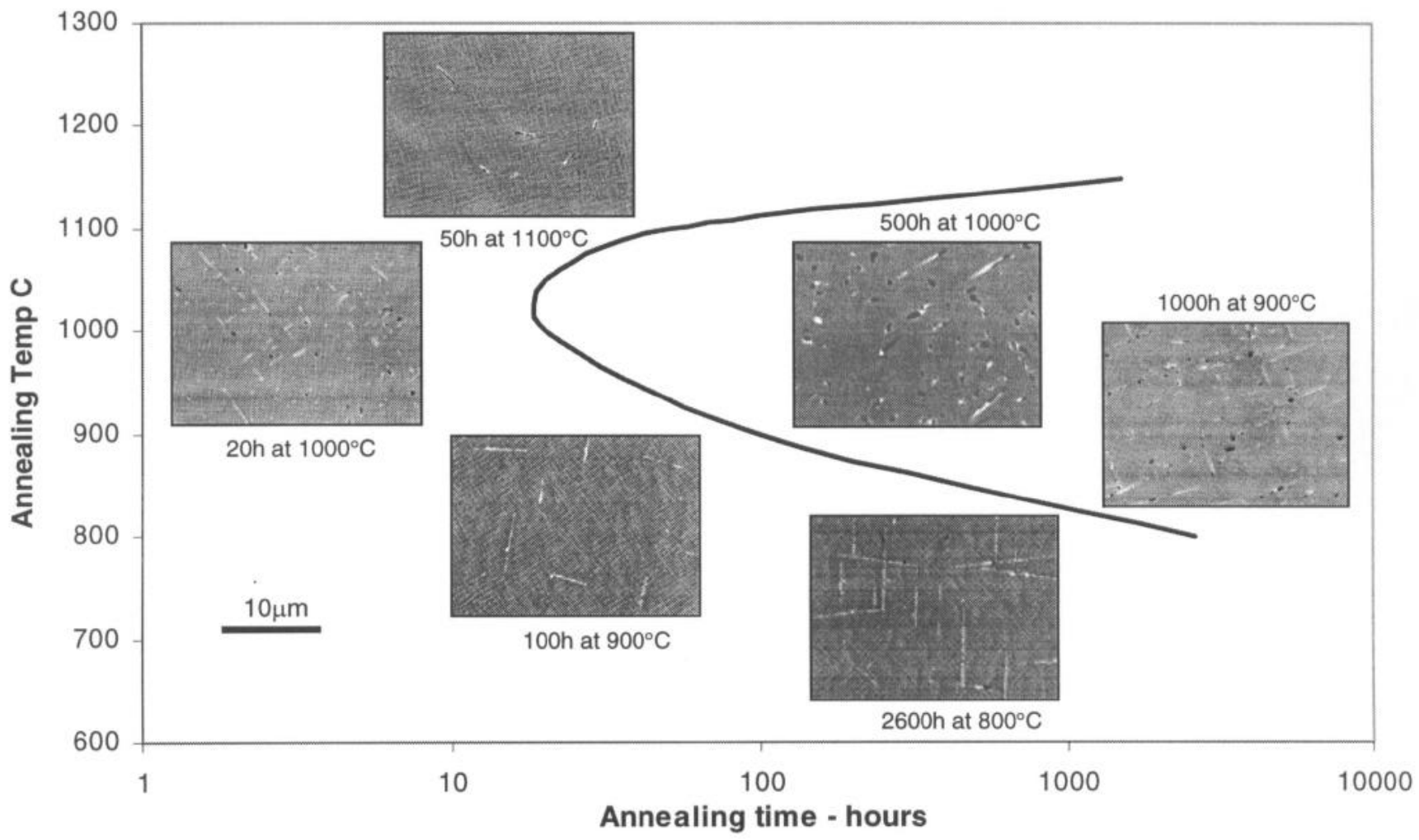

Figure 1: TTT curve for the formation of TCPs including backscattered electron SEM micrographs showing the morphology of the phases. 


\section{Results and Discussion}

\section{Transformation Kinetics}

Figure 1 shows the experimentally determined TTT curve for the onset of the formation of TCPs in RR2071. TCPs are apparent after 20 hours annealing times at temperatures of $1000^{\circ} \mathrm{C}$ $1050^{\circ} \mathrm{C}$, but are not observed after prolonged annealing at $1150^{\circ} \mathrm{C}$. The TCPs are more abundant in the dendrite cores corresponding to the retained segregation of rhenium to the core despite the full solution heat treatment [18], Figure 2.

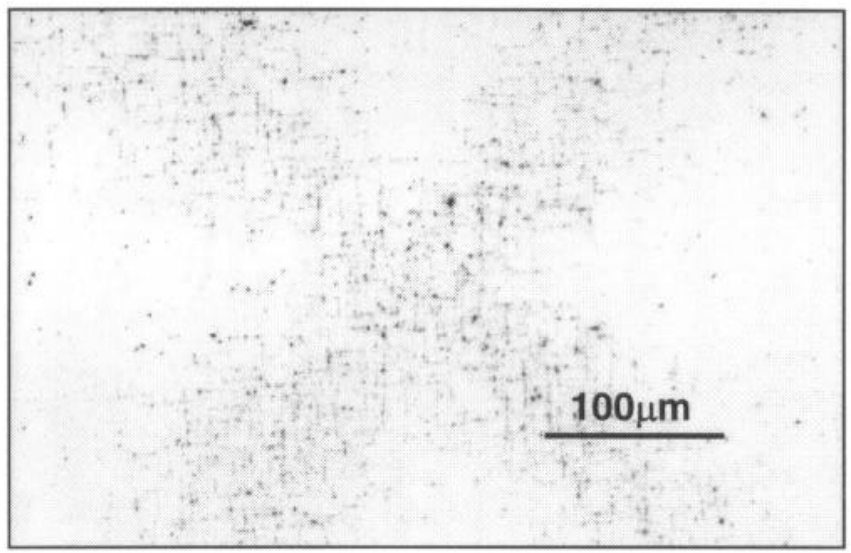

Figure 2: RR2071 annealed for $500 \mathrm{~h}$ at $1000^{\circ} \mathrm{C}$ showing the formation of TCPs at the dendrite cores. (Dark-field optical micrograph, printed in negative.)

\section{Precipitate Morphology}

The morphology of the precipitates changes with both isothermal annealing temperature, and time. This is illustrated in Figure 1, which includes back-scattered electron images of the microstructure superimposed at the appropriate position. At low temperatures (e.g. $800^{\circ} \mathrm{C}$ ) the precipitates are needle-like; closer examination shows the needles to consist of a series of discrete precipitates, accurately aligned over a distance of typically 10 $20 \mu \mathrm{m}$. These are also seen at $900^{\circ} \mathrm{C}$, in the early stages of the precipitation, (Figure 3), together with two other distinct morphologies: fine planar precipitates interspersed with more cylindrical needles and separate larger blocky precipitates. With increasing annealing time the fine planar precipitates gradually disappear leaving individual precipitates aligned over distances of $20 \mu \mathrm{m}$. The fine planar precipitates are not seen when the annealing temperature is raised to $1000^{\circ} \mathrm{C}$ and above. After $20 \mathrm{~h}$ at $1000^{\circ} \mathrm{C}$ precipitates are visible as coarse single needles. Subsequent annealing shows that these needles break up and coarsen, as shown, for example, in Figure 1 after $500 \mathrm{~h}$ at $1000^{\circ} \mathrm{C}$. At temperatures above $1000^{\circ} \mathrm{C}$ and after long annealing times at $1000^{\circ} \mathrm{C}$, the alignment of the precipitates disappears and they coarsen to become blocky. It is interesting to note that pores appear adjacent to the TCP phases as the precipitates grow; compare, for instance, the microstructure at $900^{\circ} \mathrm{C}$ after $100 \mathrm{~h}$ and $1000 \mathrm{~h}$. Pore formation is most prolific at temperatures around the nose of the TTT curve, i.e. $1000-1050^{\circ} \mathrm{C}$, but is apparent as low as $800^{\circ} \mathrm{C}$.

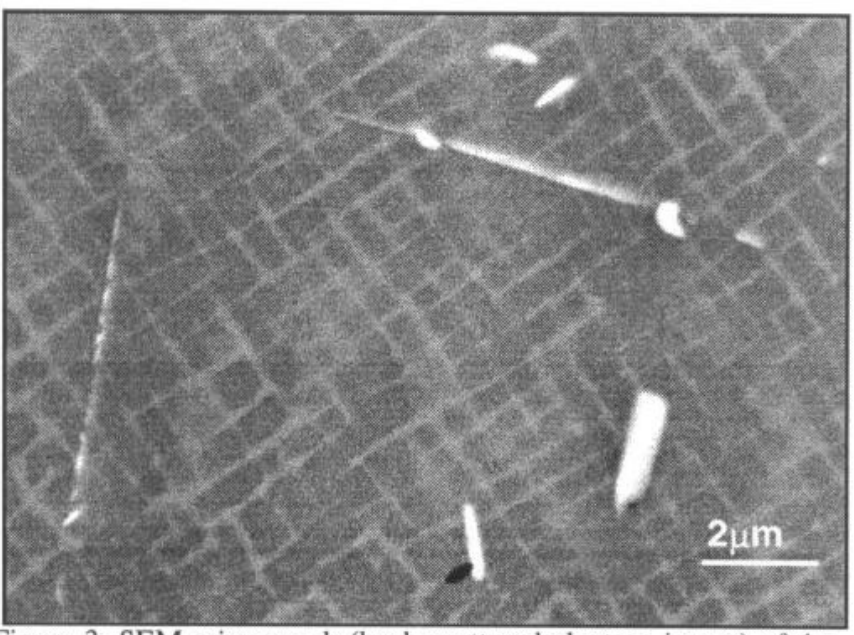

Figure 3: SEM micrograph (back-scattered electron image) of the precipitate morphology after annealing for $100 \mathrm{~h}$ at $900^{\circ} \mathrm{C}$

TEM analysis of specimens annealed at $800^{\circ} \mathrm{C}$ and $900^{\circ} \mathrm{C}$ identified the planar precipitates as thin $(\sim 30 \mathrm{~nm})$ plates of $\sigma$ phase and the co-planar, prismatic needle phases as $\mu$, Figure 4(a), 4(b), 4(c). The $\mathrm{R}$ phase was observed to form sporadically, in association with the $\sigma$ phase, see Figure 4(d).

The structure of the $\sigma$ phase in this alloy is unusual in being polycrystalline resulting in the mottled/feathery appearance of the precipitates (Figure 4(b)). Figure 5 shows the fine structure of the $\sigma$ phase sectioned in the plane of the precipitate, i.e. with the foil normal being $[1 \overline{1} 1]_{\gamma}$. All the $\sigma$ grains show the orientation relationship with respect to the $\gamma / \gamma^{\prime}$ matrix first reported in [15]. The $\sigma$ tetragonal axis $[001]_{\sigma}$ is parallel to the $[1 \overline{1} 1]_{\gamma^{\prime}}$ axis and the $[110]_{\sigma}$ axis parallel the $[110]_{\gamma},[011]_{\gamma}$ or $[10 \overline{1}]_{\gamma}$ axes. This gives a total of three different orientations for the $\sigma$ with respect to the $\gamma / \gamma^{\prime}$ matrix for each $\{111\}_{\gamma}$ plane. Each tiny grain of $\sigma$ is misoriented from the next by $30^{\circ}$ and the grain size is approximately $150 \mathrm{~nm}$. Three areas are indicated in Figure 5(a) where the orientations are clearly visible and rotated by $30^{\circ}$. The complex diffraction pattern from this form of sigma results from the superposition of the three $\sigma[001]$ patterns and this is shown in Figure 5(b)

We have found that this form of $\sigma$ nucleates very rapidly in the early stages of precipitation. We believe that this is due to a particularly low nucleation barrier for the formation of $\sigma$ resulting from the low energy of the $\sigma / \gamma$ interface on the (111) $\gamma$ plane in this orientation, thus enabling it to form as a meta-stable phase. The $\mu$ phase precipitates form as long, prismatic needles, usually in the plane of the $\sigma$ plates, and consume the $\sigma$ phase as they grow. Figure 6 shows polycrystalline $\sigma$ and $\mu$ needles in RR2071 sectioned on the (111) matrix plane. The $\sigma$ phase is on several $\{111\}_{\gamma}$ planes including that of the specimen. The long axis of the $\mu$ phase needle lies along the three-fold axis of symmetry, the $[001]_{\mu}$ axis, which is aligned within the (1i1) $\gamma$ plane of the $\gamma / \gamma^{\prime}$ matrix, close to the [10ī] $]_{\gamma}$ direction, Figure 6(b). The deviation can be seen in the micrograph by comparing the edge of the $\mu$ phase needle with the sigma plate adjacent on an intersecting 

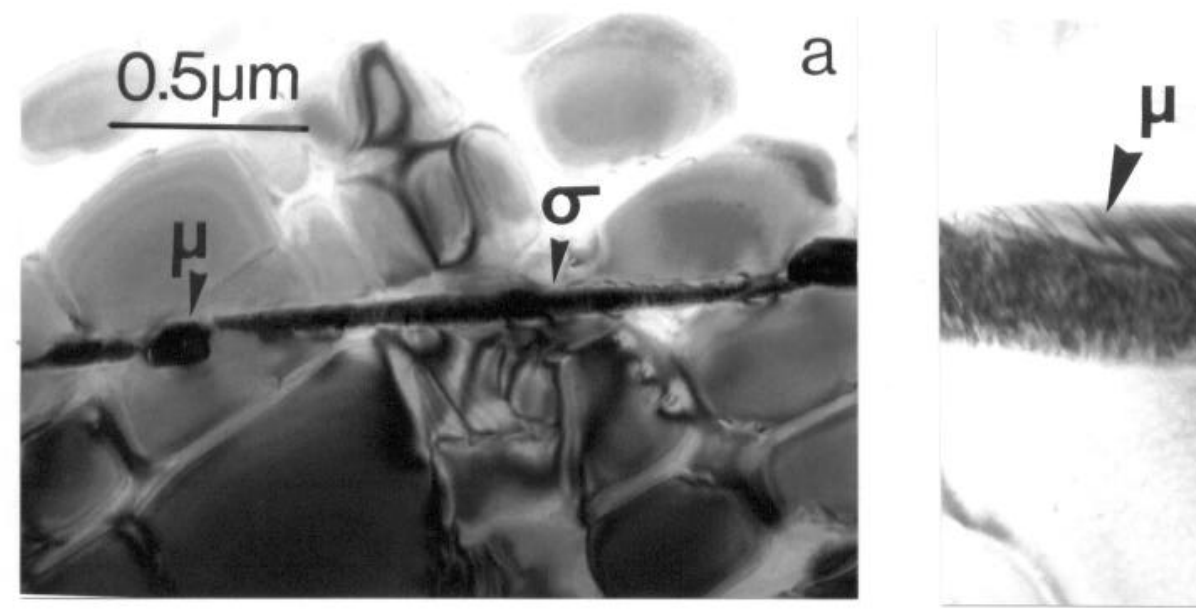

b
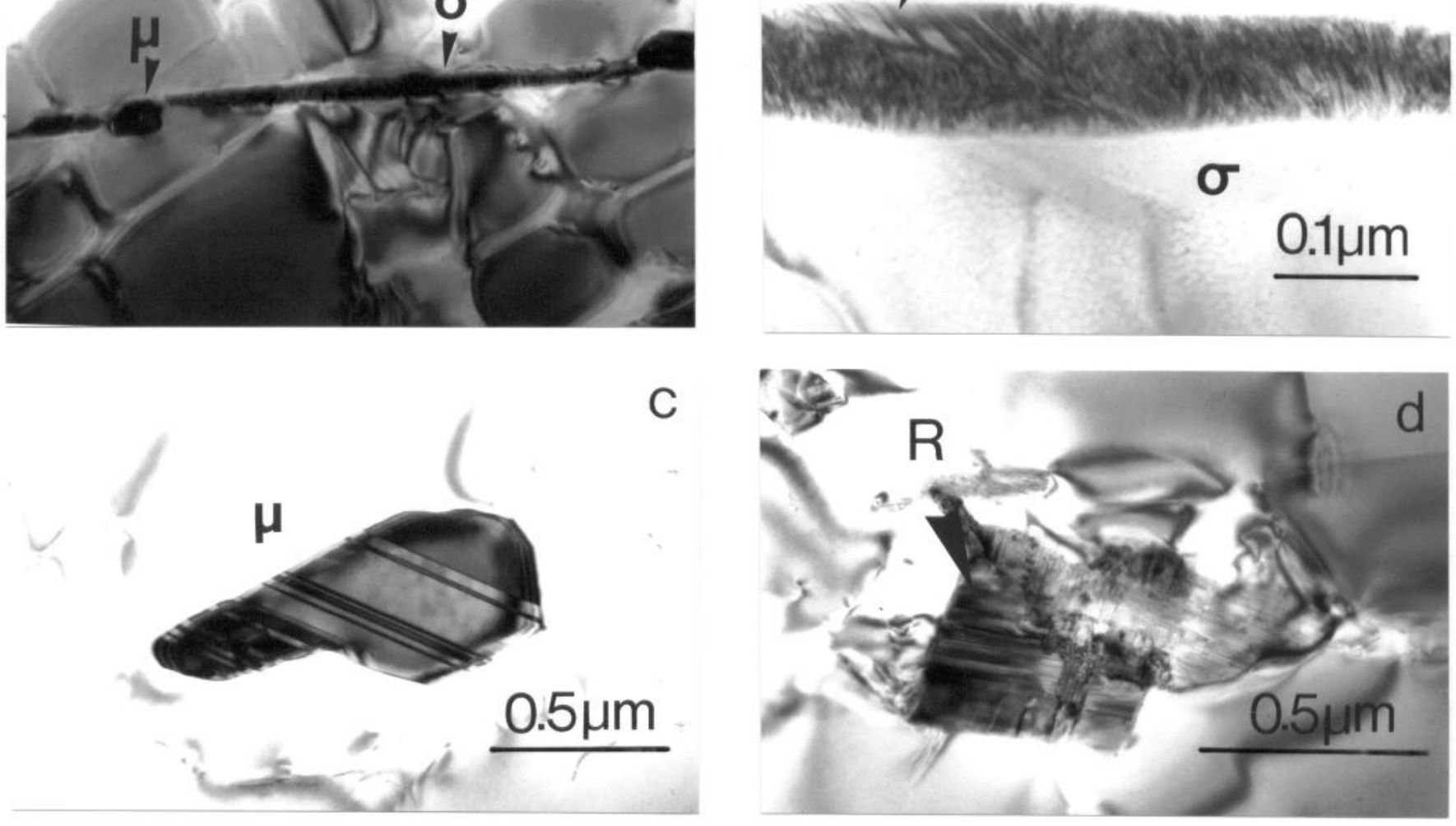

Figure 4: TEM micrographs: (a) Planar $\sigma$ with $\mu$ phase: $100 \mathrm{~h}$ at $900^{\circ} \mathrm{C}$ (b) Polycrystalline $\sigma: 100 \mathrm{~h}$ at $900^{\circ} \mathrm{C}$ (c) $\mu$ phase: $1000 \mathrm{~h}$ at $900^{\circ} \mathrm{C}$ (d) R phase in RR2071 annealed at $800^{\circ} \mathrm{C}$.
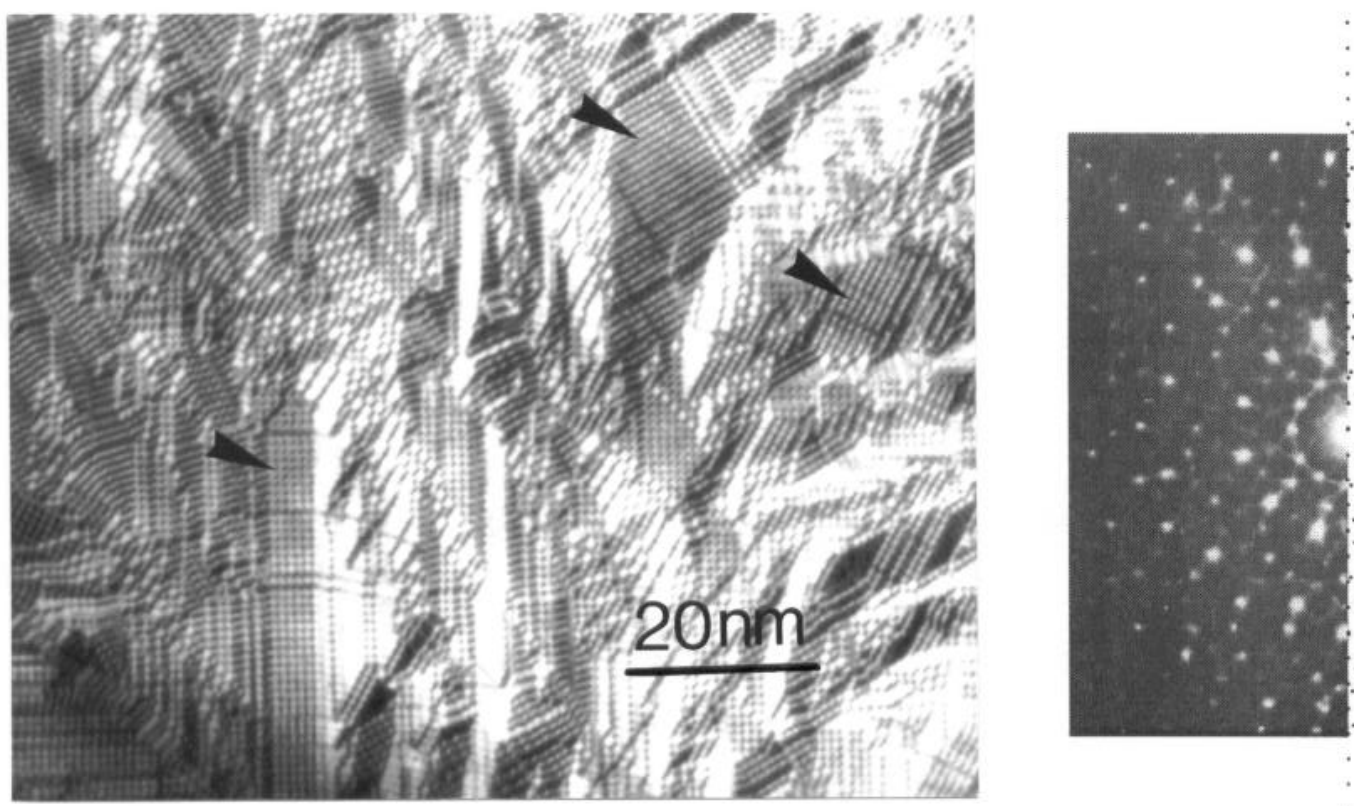

Figure 5: TEM micrograph of polycrystalline $\sigma$ sectioned on the $(001)_{\sigma} /(111)_{\gamma}$ plane showing the structure of the small grains. The diffraction pattern results from the superposition of three [001] $\sigma$ patterns rotated by $30^{\circ}$. 


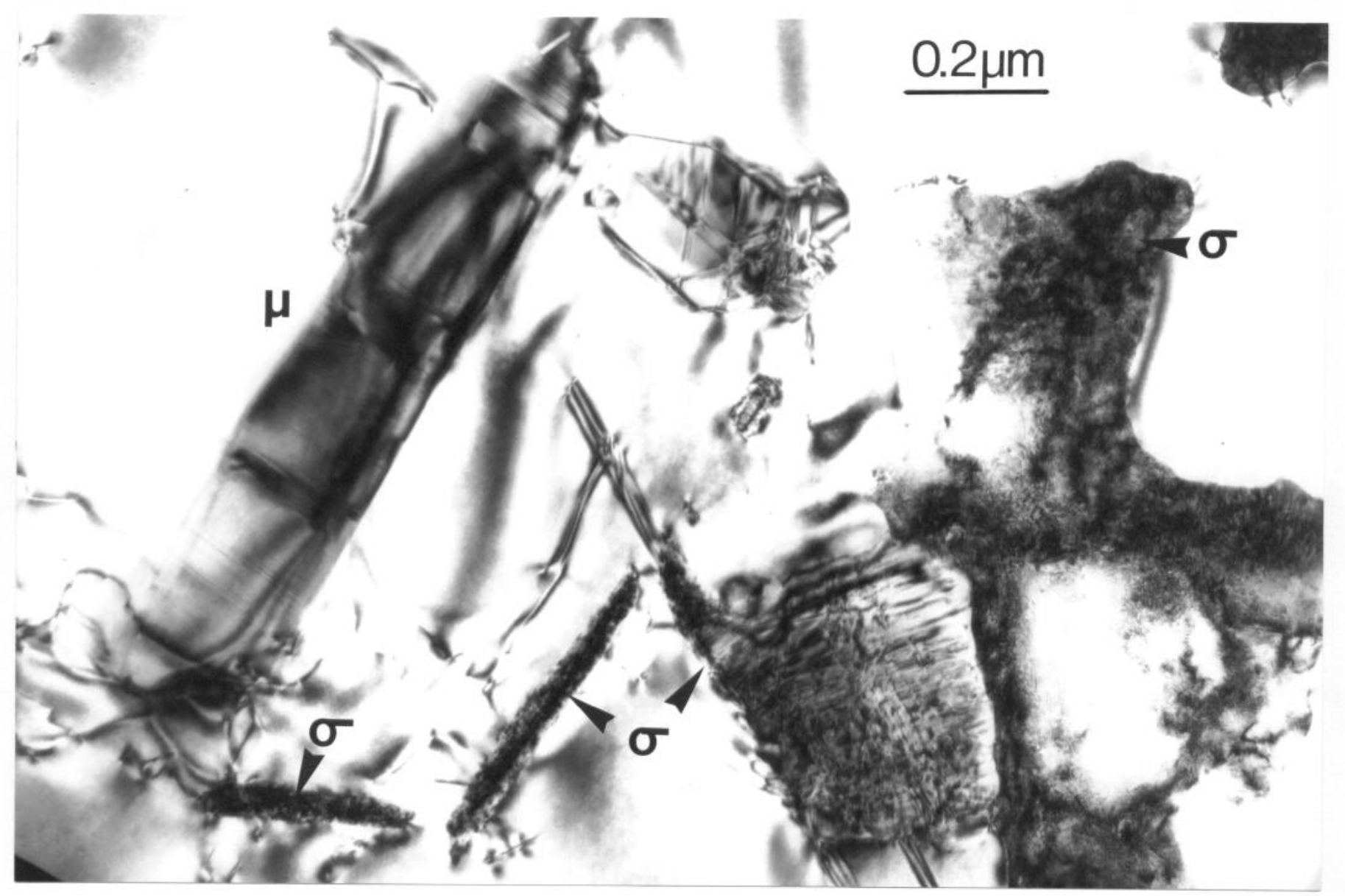

Figure 6(a)
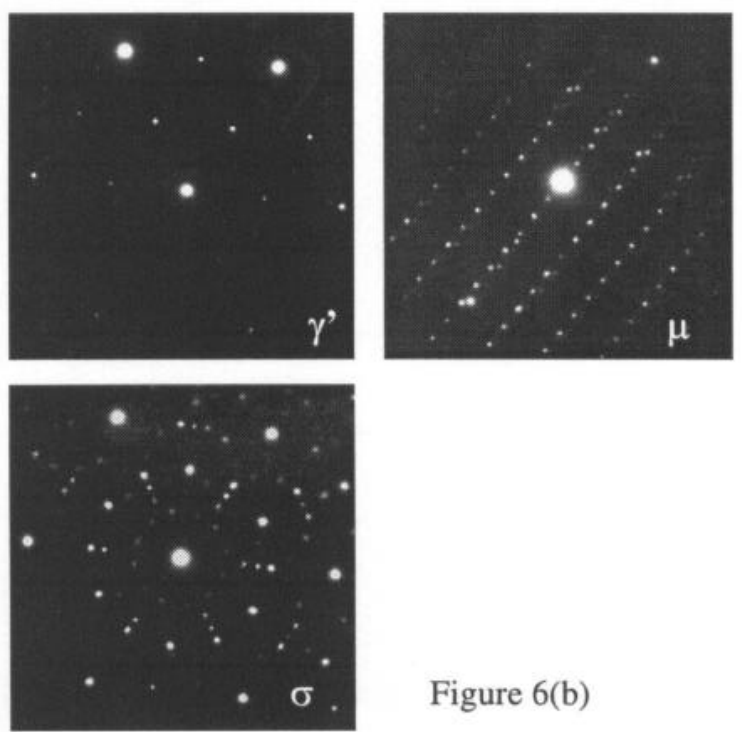

Figure 6(b)

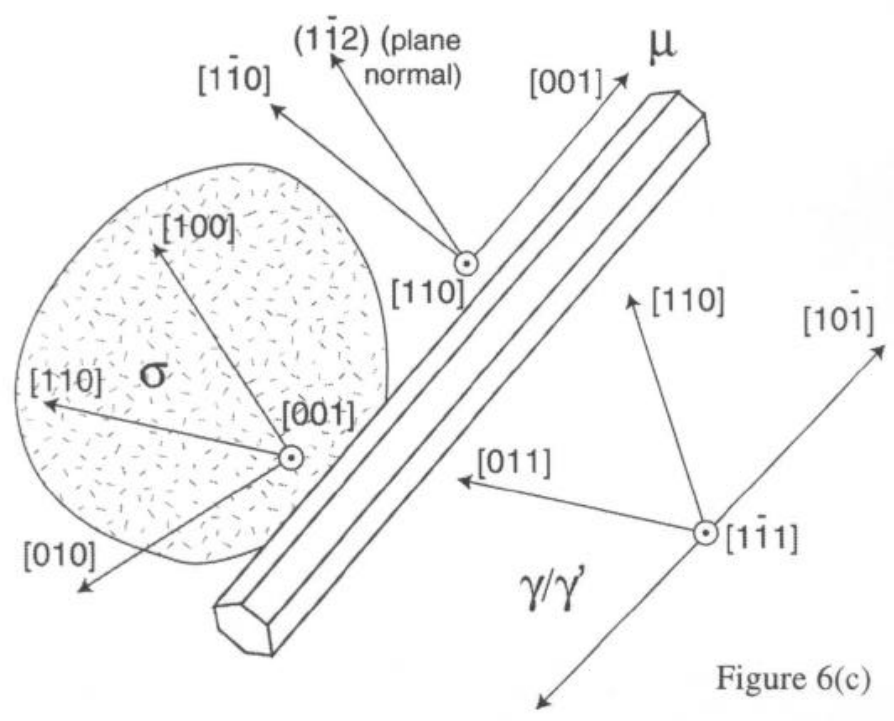

Figure 6: (a): Micrograph of RR 2071 showing planar precipitates of polycrystalline $\sigma$ on $\{111\} \gamma$ planes and needle of $\mu$ phase aligned in the (1i1) $\gamma$ plane, $3^{\circ}$ from $[10 \overline{1}]$.

(b): Diffraction patterns showing orientation relationships between $\gamma, \sigma$ and $\mu$ phases.

(c) Schematic diagram showing orientation relationship between $\mu, \sigma \& \gamma$. 
$\{111\}$ plane. The observed orientation relationship between the $\mu$ phase and the matrix can be explained if the $\mu$ phase nucleated from the $\sigma$ phase in the orientation relationship observed by Zhou et.al. [19] in an iron based superalloy. In this orientation a particularly close fitting (and potentially low energy) interface is produced between the $\mu$ and $\sigma$ phases with the interface plane parallel to the $[001]_{\sigma}$ axis, i.e. perpendicular to the sheet of polycrystalline $\sigma$. The TCP phases are aligned with $[001]_{\sigma}$ and $[110]_{\mu}$ directions normal to the (111) plane of the $\gamma / \gamma^{\prime}$. The orientation relationship reported by Zhou places the $(010)_{\sigma}$ plane parallel to the $(\overline{1} 1 \overline{2})_{\mu}$ plane. Given the orientation relationship between $\sigma$ and $\gamma$, the $[110]_{\gamma}$ lies within $3^{\circ}$ of the $[001]_{\mu}$ axis. This agrees with the orientation relationship reported Proctor [7] in CMSX-4, and presently, in the alloy RR2071. The small twinned grains indicated in Figure 4(b) may show an early stage of the formation of $\mu$ within the polycrystalline $\sigma$. The three orientation relationships are listed below and are illustrated schematically in Figure 6(c).

$\begin{array}{lr}(100)_{\sigma} / /(1 \overline{1} 2)_{\mu} \text { and }[001]_{\sigma} / /[110]_{\mu} . & \text { equiv. to Zhou et. al.[19] } \\ (001)_{\sigma} / /(1 \overline{1} 1)_{\gamma} \text { and }[110]_{\sigma} / /[011]_{\gamma} & \text { Darolia[15] } \\ {[110]_{\mu} / /(1 \overline{1} 1)_{\gamma} \text { and }[001]_{\mu} \sim * / /[011]_{\gamma}} & \text { equiv. to Procter [7] }\end{array}$

*Deviation measured as $4^{\circ}$.

The morphology and orientation of the $\mu$ phase indicate that it nucleates from within the meta-stable $\sigma$ and grows at the expense of it. After $1000 \mathrm{~h}$ at $900^{\circ} \mathrm{C}$ only traces of the planar $\sigma$ are left, but the $\mu$ precipitates remain aligned with the original $\{111\}_{\gamma}$ planes of the matrix. Of the two examples of the R phase observed in the alloy, one was found adjacent to a sheet of $\sigma$, thus indicating that it is also possible that the $\mathrm{R}$ phase can nucleate from the $\sigma$ phase.

At $950^{\circ} \mathrm{C}$ the precipitates were shown to be $\mathrm{P}$ phase with only a few examples of the $\mu$ phase. At $1000^{\circ} \mathrm{C}$ all the precipitates analysed were $\mathrm{P}$ phase. No trace of $\sigma$ was seen at either temperature. The $\mathrm{P}$ phase grows as large rectangular precipitates, elongated in the $[001]_{p}$ direction, Figure 7 . The same orientation relationship as noted by Darolia et. al. [15] was observed:

$$
(010)_{\mathrm{P}} / /(1 \overline{11})_{\gamma} \text { and }[10 \overline{2}]_{\mathrm{P}} / /[110]_{\gamma}
$$

The precipitates are faulted and twinned. The fringes spaced at $1.69 \mathrm{~nm}$ correspond to the largest of the three unit cell dimensions. The $\mathrm{P}$ phase precipitates are much larger than the $\mu$ phase seen at the lower temperatures and are typically $0.5 \mu \mathrm{m}$ in cross section.

The macroscopic form of the precipitates can be seen from SEM micrographs of the extracted residues used for X-ray analysis. The extraction process has left some of the $\gamma$ phase supporting the TCPs. At $1000^{\circ} \mathrm{C}$ the cylindrical precipitates form a threedimensional network of rods, Figure 8(a). These are beginning to thin at intervals as they break up into shorter, thicker lengths. At $850^{\circ} \mathrm{C}$ dense mats of interwoven precipitates are seen as the $\mu$ phase forms from the planar $\sigma$, Figure $8(\mathrm{~b})$.

At higher temperatures the equilibrium phase, $\mathrm{P}$, is able to form without the $\sigma$ phase or before it has grown to any appreciable size; the result is a random nucleation of precipitates and their growth in the orientation relation described above. Figure 9 shows a
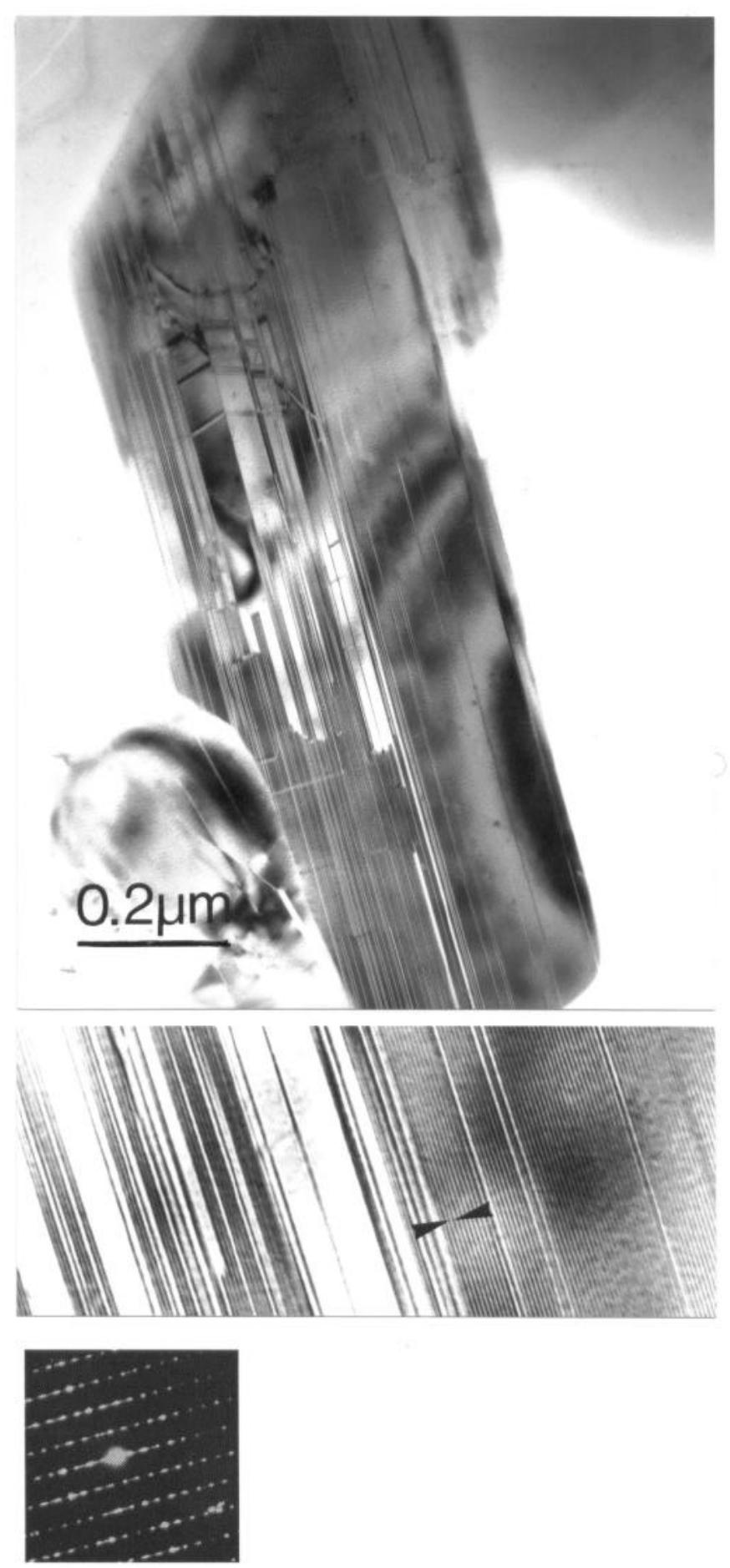

Figure 7: $\mathrm{P}$ phase precipitate in RR2071 aged at $950^{\circ} \mathrm{C}$ and orientated on the $[010]_{\mathrm{p}}$ pole. The inset shows the fringes resulting from the inclusion within the aperture of the very closely spaced diffraction spots from the $(100)_{\mathrm{p}}$ planes spaced at $1.69 \mathrm{~nm}$. Note the twinned areas which do not show fringes. 

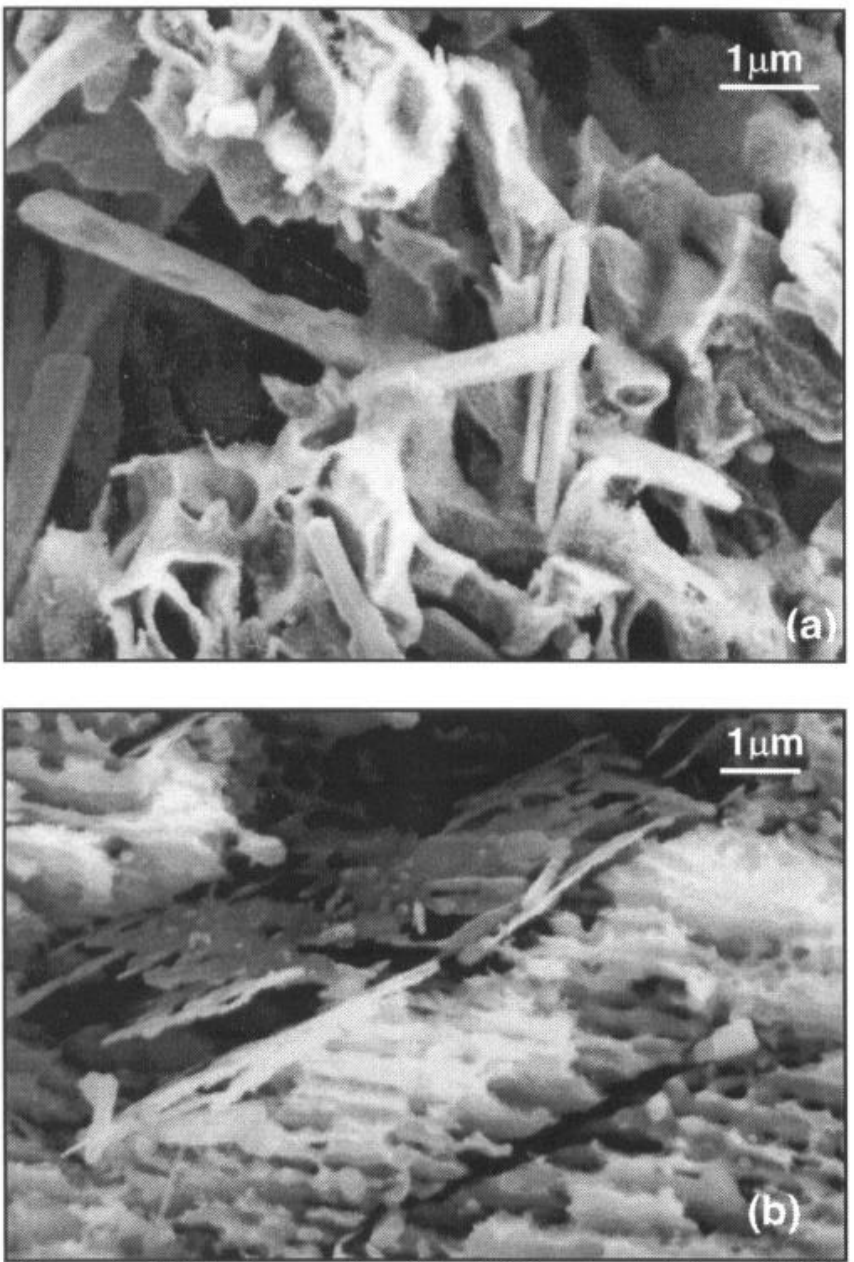

Figure 8: SEM micrographs of the TCPs extracted from RR2071 crept specimens: (a) Branching rods of $\mathrm{P}$ phase forming three dimensional network in a specimen crept at $1000^{\circ} \mathrm{C}$ for $671 \mathrm{~h}$; (b) Planar mats of $\mu$ and planar $\sigma$ in specimen crept at $850^{\circ} \mathrm{C}$ for 1972h.

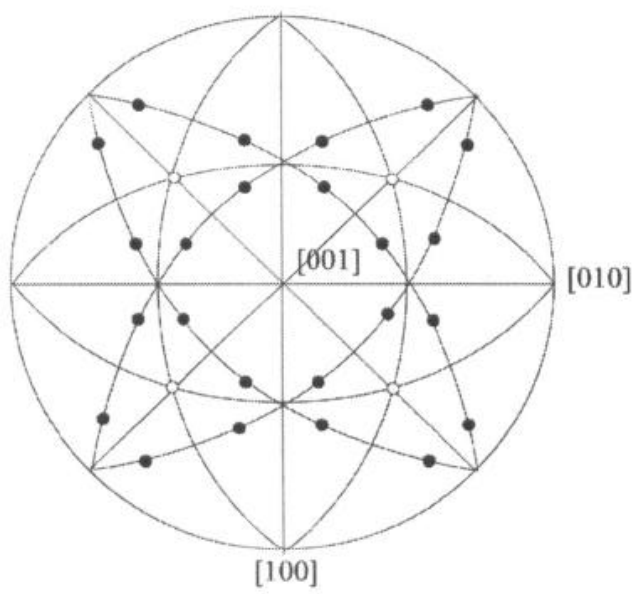

- long axis of P-phase; $\bigcirc-\{111\}$ poles in $\gamma / \gamma^{\prime}$.

Figure 9: Stereogram plotting the possible fast growth direction for the rods of the P-phase relative to the matrix. stereogram for the $\gamma / \gamma^{\prime}$ matrix identifying all the matrix directions in which the long axes of $\mathrm{P}$ phase precipitates can lie. These are grouped some $15^{\circ}$ from the $\langle 011\rangle_{\gamma}$ directions. As they grow, the precipitates can branch and intercept to form a three-dimensional network of rods. With prolonged ageing the rods thicken and segment. The result is the apparently random distribution of TCPs seen at higher temperatures and after prolonged heating at $1000^{\circ} \mathrm{C}$.

The predominance of the $\mu$ phase at low temperature $\left(<950^{\circ} \mathrm{C}\right)$ and the $\mathrm{P}$ phase at high temperature $\left(>950^{\circ} \mathrm{C}\right)$ was confirmed by $\mathrm{X}$-ray analysis of the extracted TCP residues from specimens crept for $1972 \mathrm{~h}$ at $850^{\circ} \mathrm{C}$ and $671 \mathrm{~h}$ at $1000^{\circ} \mathrm{C}$ and reported in detail in ref [18]. The lattice parameters for the $\mu$ and $\mathrm{P}$ phases in RR2071 were determined from the X-ray spectra obtained from such residues and these are summarised in Table 3.

\begin{tabular}{|l|l|l|}
\hline Hex axes & $\mu$ Reference $-\mathrm{Fe}_{7} \mathrm{~W}_{6}$ & $\mu$ in RR 2071 \\
\hline a & $0.4755 \mathrm{~nm}$ & $0.4735 \mathrm{~nm}$ \\
\hline b & $0.4755 \mathrm{~nm}$ & $0.4735 \mathrm{~nm}$ \\
\hline c & $2.583 \mathrm{~nm}$ & $2.554 \mathrm{~nm}$ \\
\hline
\end{tabular}

\begin{tabular}{|l|l|l|}
\hline & $\begin{array}{l}\text { P Reference - } \\
\mathrm{Cr}_{9} \mathrm{Mo}_{21} \mathrm{Ni}_{20}\end{array}$ & $\mathrm{P}$ in RR2071 \\
\hline a & $1.698 \mathrm{~nm}$ & $1.690 \mathrm{~nm}$ \\
\hline b & $0.475 \mathrm{~nm}$ & $0.471 \mathrm{~nm}$ \\
\hline c & $0.907 \mathrm{~nm}$ & $0.904 \mathrm{~nm}$ \\
\hline
\end{tabular}

Table 3. Lattice parameters of $\mu$ and P phase in RR2071

\section{TCP Phase Composition}

The compositions of the TCP phases have been determined by EDS analysis in the TEM, and these are given in Table 4. The values for the $\sigma, \mu$ and $\mathrm{R}$ phases were determined from specimens aged at 800 and $900^{\circ} \mathrm{C}$ and those for $\mathrm{P}$ phase at $1000^{\circ} \mathrm{C}$. Annealing times were $1000-2000 \mathrm{~h}$. The composition of the $\mu$ phase present at several temperatures showed little variation with temperature or annealing time. Where possible, several precipitates have been examined and the average value given; in the case of $\mu$ over 20 precipitates were analysed. For $\mathrm{R}$ phase the composition of only one precipitate was measured and this value is quoted. The values for the very thin precipitates of $\sigma$ contain variable amounts of $\gamma^{\prime}$ from the surrounding material and are therefore higher in aluminum and nickel. These values show a consistent pattern and a single example is quoted which shows the lowest value of the aluminum content and is hence presumed to contain the least $\gamma^{\prime}$.

Figure 10 shows the phase compositions in at \% plotted on the same axes and the 'signatures' of each of the phases can be seen. The compositions of the $\mathrm{P}$ and $\mathrm{R}$ phases are very similar and characterised by equal chromium and molybdenum concentrations. The $\mu$ phase compositions are distinctive, being high in molybdenum and low in chromium and rhenium. In contrast the $\sigma$ phase shows high chromium and low molybdenum and rhenium concentrations. 


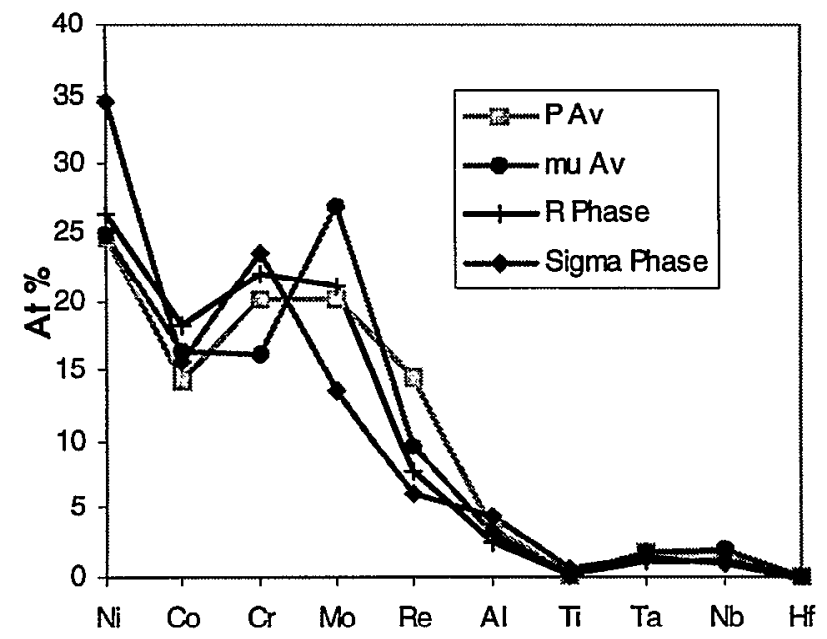

Figure 10 Graph of the compositions (at \%) of the TCP phases formed in RR2071 determined by EDX analysis in the TEM.

\begin{tabular}{|c|c|c|c|c|}
\hline & \multicolumn{4}{|c|}{ EXPERIMENTAL COMPOSITIONS } \\
\hline $\mathrm{At} \%$ & $\begin{array}{c}\text { P phase } \\
1000^{\circ} \mathrm{C}\end{array}$ & $\begin{array}{c}\mu \text { phase } \\
900^{\circ} \mathrm{C}\end{array}$ & $\begin{array}{c}\sigma \text { phase } \\
800^{\circ} \mathrm{C}\end{array}$ & $\begin{array}{c}\text { R phase } \\
800^{\circ} \mathrm{C}\end{array}$ \\
\hline $\mathrm{Ni}$ & 24.6 & 24.7 & 34.6 & 26.4 \\
\hline $\mathrm{Co}$ & 14.3 & 16.4 & 15.6 & 18.2 \\
\hline $\mathrm{Cr}$ & 20.1 & 16.1 & 23.5 & 22.0 \\
\hline $\mathrm{Mo}$ & 20.0 & 26.8 & 13.5 & 21.0 \\
\hline $\mathrm{Re}$ & 14.5 & 9.5 & 5.9 & 7.8 \\
\hline $\mathrm{Al}$ & 3.5 & 2.9 & 4.2 & 2.5 \\
\hline $\mathrm{Ti}$ & 0.1 & 0.2 & 0.6 & 0.3 \\
\hline $\mathrm{Ta}$ & 1.7 & 1.7 & 1.3 & 1.1 \\
\hline $\mathrm{Nb}$ & 1.5 & 1.8 & 1.0 & 1.1 \\
\hline $\mathrm{Hf}$ & 0.0 & 0.0 & 0.0 & 0.0 \\
\hline
\end{tabular}

Table 4: Experimental compositions of TCP phases in RR2071, at $\%$

\begin{tabular}{|c|c|c|c|c|}
\hline & \multicolumn{4}{|c|}{ CALCULATED COMPOSITIONS } \\
\hline $\mathrm{At} \%$ & $\begin{array}{c}\text { P phase } \\
1000^{\circ} \mathrm{C}\end{array}$ & $\begin{array}{c}\mu \text { phase } \\
900^{\circ} \mathrm{C}\end{array}$ & $\begin{array}{c}\sigma \text { phase } \\
800^{\circ} \mathrm{C}\end{array}$ & $\begin{array}{c}\text { R-phase } \\
800^{\circ} \mathrm{C}\end{array}$ \\
\hline $\mathrm{Ni}$ & 20.4 & 19.2 & 26.6 & 21.3 \\
\hline $\mathrm{Co}$ & 13.6 & 13.3 & 13.8 & 12.7 \\
\hline $\mathrm{Cr}$ & 25.6 & 17.1 & 37.0 & 24.1 \\
\hline $\mathrm{Mo}$ & 25.8 & 34.2 & 19.6 & 27.1 \\
\hline $\mathrm{Re}$ & 14.7 & 16.2 & 14.9 & 14.9 \\
\hline
\end{tabular}

Table 5: Calculated compositions using the 'Super 5' database, at \%

\section{Comparison with Thermocalc predictions.}

Using the results quoted here together with those from other alloys, the thermodynamic database used to predict the equilibrium structure of rhenium-containing alloys, was modified to give the version known as 'Super 5 ' [16]. The compositions of the TCP phases for the alloy RR2071 predicted using this database are given in Table 5. The 'signatures' of each of the phases are correctly predicted by the database but the experimental values for nickel are consistently higher, and the values for chromium and molybdenum lower, than predicted. At $1000^{\circ} \mathrm{C}$ and $2000 \mathrm{~h}$ the average diffusion distance for the slowest element, rhenium, in $\gamma$ is approximately $14 \mu \mathrm{m}$, of the order of the precipitate spacing. This drops to $5 \mu \mathrm{m}$ at $900^{\circ} \mathrm{C},[18,20]$ and may explain the lower experimental rhenium values found for the lower temperature phases, $\mu, \mathrm{R}$ and $\sigma$. The diffusion of the remaining TCP-forming elements is sufficiently rapid for equilibrium to be reached during the annealing time.

The relative stabilities of the various phases can be demonstrated by plotting the calculated phase occurrence as a function of the temperature for the alloy RR2071 where only one of the TCP phases is allowed to occur at any one time. Figure 11 shows that, for this alloy, the TCP phases are predicted to have very similar Gibbs free energies, and if this is indeed the case, it makes the prediction of the correct TCP phase extremely sensitive to the database parameters. Nevertheless, the predictions of the database were compared with the three similar rhenium-containing alloys for which detailed information on the TCP phase occurrence is available.

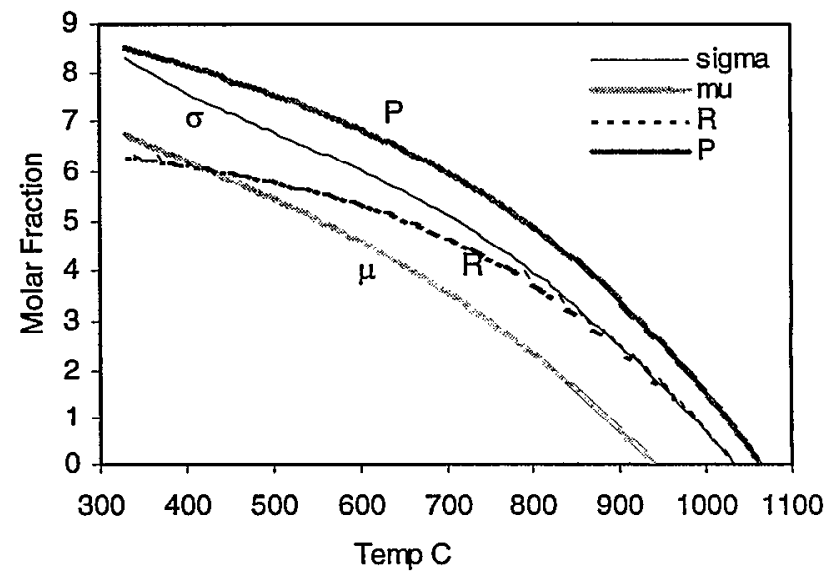

Figure 11: Calculated molar fraction of TCP phases predicted to form in the RR2071 alloy as a function of temperature with only one TCP phase being allowed to form at any one time showing the relative stability of the phases $P, R, \mu$ and $\sigma$.

The 'Super 5' database was used to predict the equilibrium TCP phases as a function of temperature for the alloys RR2071, CMSX-4 and Alloy 800 [15] and these are shown in Figure 12. RR2071 shows abundant TCP phase formation exhibiting all four of the major phases over the temperature range. The major phase at $800-900^{\circ} \mathrm{C}$ was $\mu$ with a small proportion of $\mathrm{R}$ and $\sigma$ (the $\sigma$ phase appears to be meta-stable). At $950^{\circ} \mathrm{C}$ and above, $P$ phase is the majority phase with small amounts of $\mu$ at $950^{\circ} \mathrm{C}$ but not above that temperature. Although the database correctly predicts 
the formation of P phase in RR2071 at the higher temperatures, it underestimates the stability of the $\mu$ phase at the lower temperature. The solvus for $\mathrm{P}$, predicted to be at $1060^{\circ} \mathrm{C}$, is also lower than the experimental value of $\sim 1150^{\circ} \mathrm{C}$.

In the Alloy 800 , studied by Darolia ct. al.[15] the majority phases, $\mathrm{P}$ and $\sigma$, are reported to occur together up to at least $2100^{\circ} \mathrm{F}$ or $1150^{\circ} \mathrm{C}$. The $\mu$ phase is also present in small amounts. The database predicts the occurrence of the phases $P$ and $\sigma$, both having very similar stabilities, but, again, the predicted solvus for $\mathrm{P}$ at $1050^{\circ} \mathrm{C}$ clearly underestimates the solvus of the TCP phases. In contrast, CMSX-4 [7] shows the formation of the phases $\mu$ and $R$ in small quantities. At the higher temperature of $1150^{\circ} \mathrm{C}$, equal amounts of each phase are observed but at $1050^{\circ} \mathrm{C} \mu$ is the most abundant phase. $\mathrm{P}$ phase has not been reported in CMSX-4 indicating that the replacement of tungsten by molybdenum stabilises $P$ at the expense of $R$. However as pointed out by Saunders, [14] the free energies of the phases $\sigma, R$ and $P$ are particularly close in the alloy CMSX-4, and small changes in the rhenium, chromium or tungsten levels can cause any of the phases to become the dominant predicted phase. Neither P-phase nor $\mu$ is predicted by the database. Indeed the $\mu$ phase is present in all three alloys and is the majority phase in RR2071 and CMSX-4 at lower temperatures. The stability of the $\mu$ phase is underestimated by the database. Attempts to remedy this within the existing model of the $\mu$ phase resulted in an unrealistically high rhenium content of the phase and indicate that the existing sublattice model of the $\mu$ phase requires further modification [16].

Prediction of the stability of rhenium-containing alloys with respect to TCP phases is not simply a function of equilibrium thermodynamics. The work reported here has highlighted the role that kinetics plays in the formation of TCPs. In the alloy RR2071, the precipitation of the $\sigma$ phase at $900^{\circ} \mathrm{C}$, and its subsequent disappearance, demonstrates that $\sigma$ is not the equilibrium phase, but, although it is replaced after long annealing times by $\mu$ phase, the $\sigma$ detcrmincs the morphology of the latter phase. The existence of a planar precipitate was suggested by Darolia et al to explain the inter-woven mats of $P$ and $\sigma$ precipitates parallel to \{111\} planes in Alloy 800. The difficulty of nucleating TCPs in CMSX-4 is remarked upon by Proctor [7], who observes that in CMSX-4 the $\mu$ phase precipitates are extremely large single needles up to $35 \mu \mathrm{m}$ in length. This is very much larger than any precipitates observed in RR2071. Thus the ease of nucleation of a particular phase can play an important role in the stability of an alloy in the short term and affect the morphology of the phases in the long term.

Despite the reservations outlined above, the level of detail and accuracy of the predictions from the rhenium-containing database exceeds that from other methods[21] and is in a form which can be integrated with diffusion data to provide a powerful modelling tool to incorporate kinetic effects [20,22].

\section{Summary and Conclusions}

1. RR2071 exhibits a variety of TCP phases over the temperature range. The major phase at $800-900^{\circ} \mathrm{C}$ was $\mu$ with a small proportion of $\mathrm{R}$ and $\sigma$ (the $\sigma$ phase appears to be meta-stable at $900^{\circ} \mathrm{C}$ ). At $950^{\circ} \mathrm{C}$ and above, $\mathrm{P}$ phase is the majority phase with small amounts of $\mu$ which vanish with increasing temperature.
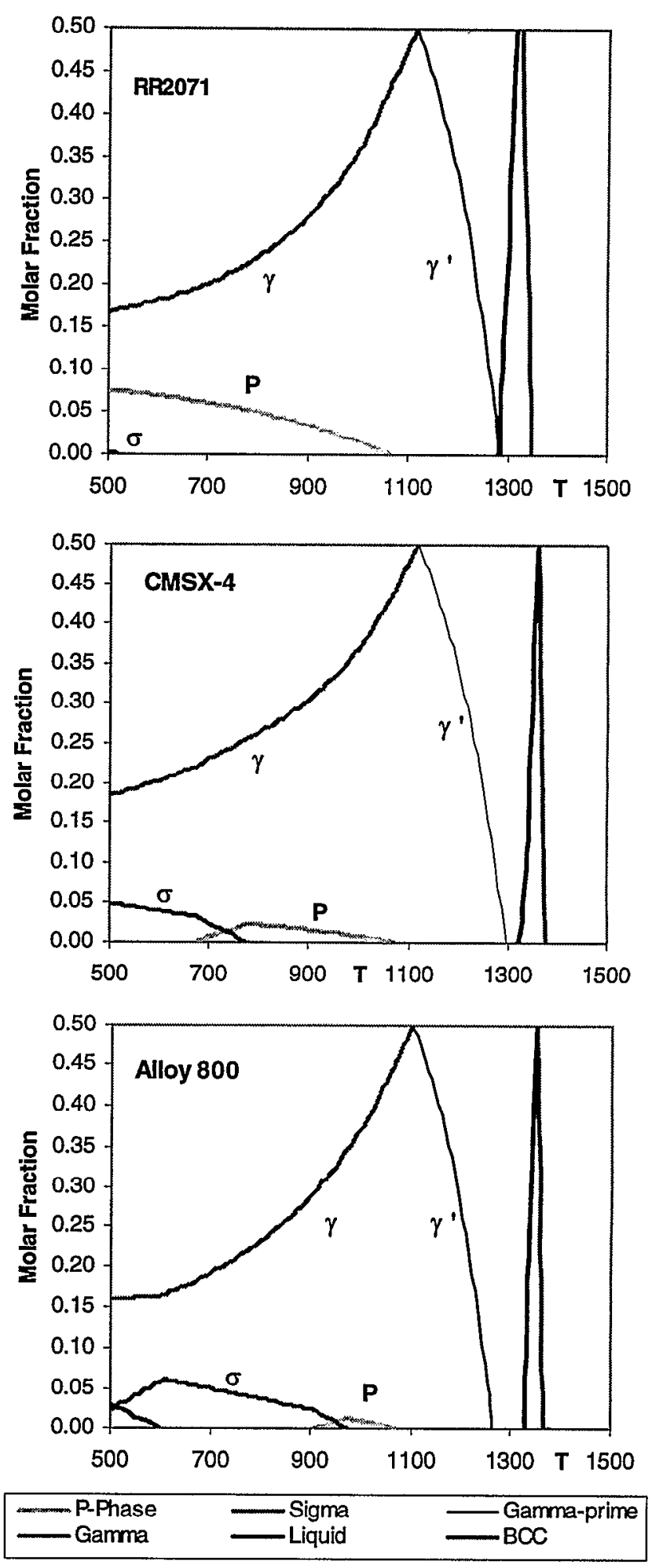

Figure 12: Equilibrium calculations using the Super 5 database to predict the phase molar fractions in RR2071, CMSX-4 and Alloy 800. 
2. The TTT diagram for TCP formation has been determined; precipitation is most rapid at $\sim 1025^{\circ} \mathrm{C}$ with significant occurrence of the $\mathrm{P}$ phase after 20 hours. No precipitation was observed at temperatures of $1150^{\circ} \mathrm{C}$ and above.

3. At lower temperatures meta-stable $\sigma$ phase is readily nucleated as very thin polycrystalline sheets. It appears to be the pre-cursor for the equilibrium phases $\mu$, and $R$.

4. $\Lambda t$ higher temperatures no evidence of $\sigma$ was found and the equilibrium phase, $P$, grows throughout the matrix to form a 3-dimensional network of branching rods. The morphology which is exhibited by this phase has been rationalised.

5. The $\mu, \sigma$ and $\mathrm{P}$ phases are readily distinguished by composition: $\mu$ is rich in Mo (or W) $\sigma$ is rich in chromium and low in molybdenum, and $P$ and $R$ both have roughly equal concentrations of molybdenum and chromium. Increasing the alloy molybdenum/tungsten ratio stabilises $\mathrm{P}$ at the expense of $\mathrm{R}$.

6. The modified database for the rhenium-containing alloys has proved reasonably successful at predicting the occurrence of the $P$ and $\sigma$ phases but underestimates the stability of these phases. However the calculations using the current 'Super 5' database failed to predict the occurrence of the $\mu$ phase in any of the alloys examined, and the model for this phase requires further development.

\section{Acknowledgements}

The authors thank the Cambridge Commonwealth Trust, the Engineering Physical Sciences Research Council (EPSRC), RollsRoyce plc and the Defence Evaluation \& Research Agency (DERA) for sponsoring this work. We would also like to thank Nigel Saunders of Thermotech for many valuable discussions concerning the thermodynamic modelling.

\section{$\underline{\text { References }}$}

1. A.F. Giamei and D.L. Anton, "Rhenium Additions to a Nibase Superalloy: Effccts on Microstructure", Metall Trans 16A, (1985), 1997-2005.

2. K. Harris, G.L. Erickson, S.L. Sikkenga, W. Brentnall, J.M. Aurrecoechea and K.G. Kubarych, "Development of the rhenium-containing superalloys CMSX-4 \& CM186LC for single crystal blade and directionally solidified vane applications in advanced turbine engines", Superalloys, ed. S.D. Antolovitch et al., (Warrendale, PA, USA, 1992), 297 306.

3. A.K. Sinha, "Topologically Close-Packed Structures of Transition Metal Alloys", Progress in Materials Science, (1972), 79-185.

4. F.C. Frank and J.S. Kasper, Acta. Crystall., 12, (1959), 483.

5. S.T. Wlodek, Trans. of ASM, 57, (1964), 110-119.

6. E.W. Ross, Journal of Metals, 19, (1967), 12-14.

7. C. Proctor, "Formation and effects of intermetallics in the Recontaining superalloy CMSX-4" (PhD Thesis, University of Cambridge, 1993)
8. M. Pessah, P. Caron and T. Khan, "Effect of $\mu$ phase on the mechanical properties of a nickel-based single crystal superalloy" Superalloys (1992), ed. S.D. Antolovitch et al., (Warrendale, PA, USA,1992) 567-576.

9. T. Yokokawa, M. Osawa, H. Murakami, T. Kobayashi, Y. Koizumi, T. Yamagata and H. Harada, "Design of high Re containing single crystal superalloys for industrial gas turbines", Materials for Advanced Power Engineering, ed. J. Lecomte-Beckers, F Schubert and P.J. Ennis, Forschungszentrum, Julich, Germany, (1998), 1121-1128.

10. B. Sundman, B. Jansson and J. Andersson, "The Thermocalc Databank System", Calphad, 9 (1985), 153-190.

11. N. Saunders, Phil. Trans. Roy. Soc. Lond A, 351, (1995), 543561.

12. N. Saunders, "Phase diagram calculations for Ni-based superalloys", Superalloys, ed. R.D. Kissinger, D.J. Deye, D.L. Anton, A.D. Cetel, M.V. Nathal, T.M. Pollock and D.M. Woodford, (Warrendale PA, USA, 1996), 101-109.

13. N.J. Saunders and A.P. Miodownik, "Calphad, A Comprehensive Guide", Pergamon Press, (1998).

14. N. Saunders, "Modelling of Nickel-base Superalloys", Advanced Materials and Processes, 156, 9, (1999), 29-31.

15. R. Daralia, D.F. Lahrman and R.D. Field, "Formation of topologically close packed phases in Ni-based single crystals", Superalloys, ed. S. Reichman, D.N. Duhl, G. Maurer, S. Antolovich and C. Lund, (Warrendale PA, USA, 1988) 255-264.

16. N. Saunders, C.J. Small, "Computer modeling of Ni-based superalloy phase equilibria" Priv. Com. (1999) Thermotech plc, Surrey Technology Centre, 40 Occam Road, The Surrey Research Park, Guildford, Surrey GU2 5YG, UK.

17 R.C. Reed, M.P. Jackson and Y.S. Na, "Characterisation and Modelling of the Precipitation of the Sigma Phase in Udimet 720 and Udimet 720Li", Metallurgical and Materials Transactions, 30A, (1999), 521-533.

18 M.S.A. Karunaratne, "Diffusional phenomena in Ni-based superalloys", (PhD Thesis, University of Cambridge, 2000).

19. D.S. Zhou, H.Q. Ye and K.H. Kuo, "An HREM study of the intergrowth structures of $\sigma$-related phases and the $\mu$ phase", Phil. Mag. A, 57 (6), (1988), 907-922.

20. M.S.A. Karunaratne, P. Carter and R.C. Reed, "Interdiffusion in the FCC-A1 phase of the $\mathrm{Ni}-(\mathrm{Re}, \mathrm{Ta}, \mathrm{W})$ binary systems between $900^{\circ} \mathrm{C}$ and $1300^{\circ} \mathrm{C}$, Mat. Sci. and Eng., A281, (1999), 229-233.

21. H. Harada, K. Ohno, T. Yamagata, T. Yokokawa and M. Yamazaki, "Phase calculation and its use in alloy design program for Ni-based superalloys", Superalloys, ed. S. Reichman, D.N. Duhl, G. Maurer, S. Antolovich and C. Lund, (Warrendale PA, USA, 1988), 733-742.

22. N..Matan, H. Winand, P. Carter, M. Karunaratne, P.Bogdanoff and R.C. Reed, "A coupled thermodynamic/kinetic model for diffusional processes in superalloys", Acta Mater., 46 (13), (1998), 4587-4600. 